\title{
Pharmacological management of chronic neuropathic pain: Revised consensus statement from the Canadian Pain Society
}

\author{
DE Moulin MD, A Boulanger MD, AJ Clark MD, H Clarke MD PhD, T Dao DMD PhD, GA Finley MD, \\ A Furlan MD PhD, I Gilron MD MSc, A Gordon MD, PK Morley-Forster MD, BJ Sessle MDS PhD, P Squire MD, \\ J Stinson RN PhD, P Taenzer PhD, A Velly DDS PhD, MA Ware MD, EL Weinberg MD, OD Williamson MBBS
}

DE Moulin, A Boulanger, AJ Clark, et al. Pharmacological management of chronic neuropathic pain: Revised consensus statement from the Canadian Pain Society. Pain Res Manag 2014;19(6):328-335.

BACKGROUND: Neuropathic pain $(\mathrm{NeP})$, redefined as pain caused by a lesion or a disease of the somatosensory system, is a disabling condition that affects approximately two million Canadians.

OBJECTIVE: To review the randomized controlled trials (RCTs) and systematic reviews related to the pharmacological management of $\mathrm{NeP}$ to develop a revised evidence-based consensus statement on its management. METHODS: RCTs, systematic reviews and existing guidelines on the pharmacological management of $\mathrm{NeP}$ were evaluated at a consensus meeting in May 2012 and updated until September 2013. Medications were recommended in the consensus statement if their analgesic efficacy was supported by at least one methodologically sound RCT (class I or class II) showing significant benefit relative to placebo or another relevant control group. Recommendations for treatment were based on the degree of evidence of analgesic efficacy, safety and ease of use.

RESULTS: Analgesic agents recommended for first-line treatments are gabapentinoids (gabapentin and pregabalin), tricyclic antidepressants and serotonin noradrenaline reuptake inhibitors. Tramadol and controlledrelease opioid analgesics are recommended as second-line treatments for moderate to severe pain. Cannabinoids are now recommended as third-line treatments. Recommended fourth-line treatments include methadone, anticonvulsants with lesser evidence of efficacy (eg, lamotrigine, lacosamide), tapentadol and botulinum toxin. There is support for some analgesic combinations in selected $\mathrm{NeP}$ conditions.

CONCLUSIONS: These guidelines provide an updated, stepwise approach to the pharmacological management of NeP. Treatment should be individualized for each patient based on efficacy, side-effect profile and drug accessibility, including cost. Additional studies are required to examine head-to-head comparisons among analgesics, combinations of analgesics, long-term outcomes and treatment of pediatric, geriatric and central NeP.

Key Words: Analgesic agents; Neuropathic pain; Randomized controlled trials

$\mathrm{N}$ europathic pain $(\mathrm{NeP})$ has been redefined as pain caused by a lesion or a disease of the somatosensory system, and may be generated by either the peripheral or central nervous system, or both (1). Pain may be a manifestation of nerve injury, but there are few predictors to indicate which patients will develop this complication. For example, $50 \%$ of diabetic patients develop neuropathy during the course of their illness, but only approximately $15 \%$ report actual dysesthesias or pain (2). Similarly, breast surgery with transection of the intercostal brachial nerve results in $\mathrm{NeP}$ in up to $50 \%$ of patients (3). Previous prevalence estimates indicated that $2 \%$ to $3 \%$ of the population in the developed world experience $\mathrm{NeP}(4,5)$. However,
La prise en charge pharmacologique de la douleur neuropathique chronique : une déclaration de consensus révisée de la Société canadienne de la douleur

HISTORIQUE : La douleur neuropathique (DNe), redéfinie comme une douleur causée par une lésion ou une maladie du système somatosensoriel, est un trouble invalidant dont sont affligés environ deux millions de Canadiens. OBJECTIF : Examiner les essais aléatoires et contrôlés (EAC) et les analyses systématiques liées à la prise en charge pharmacologique de la DNe pour préparer une déclaration de consensus révisée, fondée sur des faits probants, à l'égard de sa prise en charge.

MÉTHODOLOGIE : Les EAC, les analyses systématiques et les lignes directrices sur la prise en charge pharmacologique de la $\mathrm{DNe}$ ont été évaluées lors d'une réunion de consensus en mai 2012, puis mises à jour en septembre 2013. Les médicaments étaient recommandés dans le document de consensus si leur efficacité analgésique était soutenue par au moins une EAC solide sur le plan méthodologique (classe I ou II), qui démontrait des avantages marqués par rapport à un placebo ou à un autre groupe témoin pertinent. Les recommandations thérapeutiques reposaient sur la qualité des preuves d'efficacité analgésique, d'innocuité et de facilité d'utilisation. RÉSULTATS : Les analgésiques recommandés pour le traitement de première intention sont les gabapentinoïdes (gabapentine et prégabaline), les antidépresseurs tricycliques et les inhibiteurs spécifiques du recaptage de la sérotonine et de la noradrénaline. Le tramadol et les opioïdes à libération contrôlée sont recommandés en deuxième intention pour la douleur modérée à grave. Les cannabinoïdes sont désormais recommandés en troisième intention, tandis que la méthadone, les anticonvulsivants dont l'efficacité est moins attestée (p. ex., lamotrigine, lacosamide), le tapentadol et la toxine botulique sont recommandés en quatrième intention. Certaines polythérapies analgésiques sont acceptées pour traiter des troubles de $\mathrm{DNe}$ particuliers. CONCLUSIONS : Ces lignes directrices fournissent une démarche mise à jour et graduelle pour la prise en charge pharmacologique de la DNe. Le traitement devrait être personnalisé en fonction de chaque patient, compte tenu de l'efficacité, du profil d'effets secondaires et de l'accessibilité du médicament, y compris son coût. D'autres études s'imposent pour faire des comparaisons directes entre analgésiques et examiner des combinaisons d'analgésiques, les résultats à long terme et le traitement de la $\mathrm{DNe}$ en pédiatrie, de la $\mathrm{DNe}$ en gériatrie et de la $\mathrm{DNe}$ centrale.

newer studies using population-based questionnaires estimate a higher rate of $4 \%$ to $8 \%(6,7)$, which suggest that approximately two million Canadians experience this disabling condition. Even more striking is that the prevalence of $\mathrm{NeP}$ is likely to increase for a number of reasons. The population is aging, and a pandemic of obesity is occurring in the developed world. These factors are largely responsible for increasing rates of postherpetic neuralgia and painful diabetic neuropathy $(8,9)$. In addition, survival rates are increasing among cancer patients, and many of the medical and surgical interventions used in the treatment of cancer (including chemotherapy) can cause $\mathrm{NeP}(10)$.

Author affiliations are presented in Appendix B

Correspondence: Dr Dwight Moulin, Departments of Clinical Neurological Sciences, Victoria Hospital, 800 Commissioners Road East, London,

Ontario N6A 5W9. Telephone 519-685-8661, fax 519-685-8636, e-mail dwight.moulin@lhsc.on.ca

OPEN $\bigcirc$ ACCESS

This open-access article is distributed under the terms of the Creative Commons Attribution Non-Commercial License (CC BY-NC) (http:// creativecommons.org/licenses/by-nc/4.0/), which permits reuse, distribution and reproduction of the article, provided that the original work is properly cited and the reuse is restricted to noncommercial purposes. For commercial reuse, contact support@pulsus.com 


\section{METHODS}

In 2007, the Canadian Pain Society (CPS) produced the first guidelines on pharmacological management of $\mathrm{NeP}$ tailored to the clinical practices of Canadian health professionals including analgesic agents specifically available in Canada (11). A consensus meeting was held in Whistler, British Columbia under the direction of the Neuropathic Pain Special Interest Group of the CPS in May 2012 to update these guidelines, given the plethora of systematic reviews and meta-analyses published since 2007 (Appendix A). There is also recent evidence from community-based studies that management of $\mathrm{NeP}$, including postherpetic neuralgia, is not consistent with evidence-based recommendations (12). Funding for this consensus meeting was provided by the Neuropathic Pain Special Interest Group of the CPS. This involved a multidisciplinary group of individuals with research and clinical expertise relevant to the pathophysiology and management of NeP. This group met to review the randomized controlled trials (RCTs) and systematic reviews related to the pharmacological management of $\mathrm{NeP}$ to develop a revised evidence-based consensus statement on the management of $\mathrm{NeP}$ (13). Subsequent literature was reviewed by the group until September 2013 .

Systematic searches on Medline and Cochrane databases were conducted to identify recent systematic reviews, meta-analyses and treatment recommendations, guidelines and/or consensus statements published since the first 2007 CPS consensus statement. Other selected publications and references were also considered. Medications could be recommended in the consensus statement if their analgesic efficacy was supported by at least one methodologically sound RCT (class I or class II) showing significant benefit relative to placebo or another relevant control group. Trials were excluded if they represented uncontrolled studies, had sample sizes of $<10$ patients or studied cancer $\mathrm{NeP}$ except for well-defined postsurgical pain syndromes (eg, postmastectomy pain syndrome) and chemotherapy-induced $\mathrm{NeP}$. Trials were also excluded if they studied trigeminal or glossopharyngeal neuralgia because these conditions have their own specific medical and surgical treatments (14). The initial draft of the present manuscript was prepared by the first author and subsequent revisions were based on feedback from the other authors until consensus was achieved.

The current guidelines are based on quality of evidence of analgesic efficacy, side-effect profiles and ease of use. Medications were considered to be first line if there was high-quality evidence of efficacy (at least one class I study or two consistent class II studies - level of recommendation grade $\mathrm{B}$ or better) (15); positive results in at least two NeP models (16); and if they were considered to be straightforward and of sufficient tolerability to prescribe and monitor. Medications were considered to be second or third line if there was high-quality evidence of efficacy, but the medication required more specialized follow-up and monitoring. Fourth-line treatments had at least one positive RCT, but require further study. A limitation of this algorithmic classification is that grading of tolerability and ease of use was based solely on consensus opinion of the authors.

Target users for these guidelines are physicians, nurse practitioners and other allied health care individuals involved in the management of $\mathrm{NeP}$. These guidelines have been endorsed by the Canadian Pain Coalition, an advocacy group for patients living with chronic pain. The published guidelines will be disseminated through various websites, including the CPS website, and reprints will be made available to undergraduate and postgraduate trainees, and practicing health care workers attending continuing medical education events. They will be updated periodically by the Neuropathic Pain Special Interest Group of the CPS.

\section{CLINICAL CHARACTERISTICS AND DIFFERENTIAL DIAGNOSES OF NeP}

The clinical features of $\mathrm{NeP}$ can be divided into spontaneous pain and stimulus-evoked pain. Spontaneous pain is commonly described as burning or intense tightness with superimposed shooting or lancinating pain. Stimulus-evoked pain includes allodynia, defined as painful sensations in response to a normally nonpainful stimulus, and hyperalgesia, defined as increased pain sensitivity in response to a normally painful stimulus. Superimposed autonomic features, such as alterations in temperature, colour and sweating as well as the development of trophic changes, suggest a diagnosis of reflex sympathetic dystrophy or complex regional pain syndrome (17).

The differential diagnosis of $\mathrm{NeP}$ is extensive and includes central and peripheral causes. Examples of central NeP include poststroke pain ('thalamic pain syndrome'), pain related to multiple sclerosis and pain due to spinal cord injury. Common causes of peripheral $\mathrm{NeP}$ include painful diabetic neuropathy, postherpetic neuralgia and surgically induced $\mathrm{NeP}$, following thoracotomy, amputation, breast surgery and back surgery sometimes associated with nerve root fibrosis.

The diagnosis of $\mathrm{NeP}$ is based primarily on the patient's history and physical examination. Postherpetic neuralgia and painful diabetic neuropathy are typically easy to diagnose when there is a history of shingles and diabetes mellitus, respectively. However, pain radiating into an extremity can be either referred myofascial pain or $\mathrm{NeP}$, and these can be much more challenging to diagnose. Simple questionnaires based on sensory descriptors and sensory examination have been developed to differentiate between somatic pain and $\mathrm{NeP}$. Instruments such as the Douleur Neuropathique 4 and the Leeds Assessment of Neuropathic Symptoms and Signs have been shown to be valid and reliable discriminators of $\mathrm{NeP}(18,19)$. In addition, the presence of true weakness (sometimes difficult to differentiate from pain-related or antalgic weakness), reduced or absent reflexes, allodynia and hyperalgesia all favour a diagnosis of NeP. Electromyography and nerve conduction studies are sometimes useful to provide more objective evidence of nerve injury, although electromyography study results are often normal in small-fibre neuropathies. Guidelines are available to determine the diagnostic certainty of $\mathrm{NeP}$ (possible, probable or definite) based on history, sensory signs, neurophysiological testing and neuroimaging (1).

\section{GENERAL CONSIDERATIONS}

Because NeP can be severe and unrelenting, it is important to recognize and treat comorbidities such as anxiety and depression. It is also important to recognize secondary treatment goals such as improving sleep, ability to function and overall quality of life. However, treatment goals must be realistic. Caregivers should validate the patient's pain to gain their trust and should set realistic treatment goals. This is typically straightforward from the caregiver's point of view because most $\mathrm{NeP}$ states are based on well-defined injuries to the nervous system. The primary goal in most cases is to make the pain 'bearable' or 'tolerable' - not to eliminate the pain. Such goal setting can make a considerable difference in patient satisfaction when pharmacological treatments are instituted.

Due to the lack of head-to-head trials to guide treatment choices, one approach to estimate the relative efficacy of analgesic agents in RCTs is to use the number needed to treat (NNT) - the number of patients that need to be treated with a certain drug to provide one additional patient with at least $50 \%$ pain relief relative to the comparator group. The NNT is used to estimate treatment efficacy, recognizing that there are limitations to this methodology including variability in RCTs (eg, crossover versus parallel design) and the shortterm nature of most RCTs. Another approach to estimate efficacy is to determine the effect size - defined as the mean difference between active agent and placebo divided by the SD. The effect size can be classified as small $(<0.5)$, medium $(0.5$ to $<0.8)$ or large $(\geq 0.8)(20)$.

Appendix A summarizes the results of a systematic search of systematic reviews, meta-analyses and treatment recommendations, guidelines and/or consensus statements published since the first 2007 CPS consensus statement. These results were reviewed and approved by two coauthors (DEM and IG) and provide the basis for the consensus statement presented here.

\section{FIRST-LINE ANALGESICS}

Two classes of medications are recommended for first-line treatment in the management of $\mathrm{NeP}$ - anticonvulsants and certain antidepressants. 


\section{Anticonvulsants}

The gabapentinoids, gabapentin and pregabalin, bind to presynaptic voltage-gated calcium channels in the dorsal horn, reducing the release of excitatory neurotransmitters such as glutamate and substance P (21). These agents have been studied in large clinical trials, although mainly in the management of painful diabetic neuropathy and postherpetic neuralgia. Gabapentin has shown efficacy in three trials involving painful diabetic neuropathy and two trials involving postherpetic neuralgia (22); however, four RCTs involving gabapentin have been negative, including a trial of gabapentin in chemotherapyinduced painful neuropathy (23-26). The combined NNTs for gabapentin in the management of painful polyneuropathy and postherpetic neuralgia were 6.4 and 4.3 , respectively (27).

Pregabalin is an analogue of gabapentin, with the same mechanism of action, but it manifests linear pharmacokinetics and has higher affinity for the presynaptic calcium channel. Four studies have shown that pregabalin provides significant pain relief and improved quality of life in painful diabetic neuropathy (28) and an additional four trials have shown efficacy in postherpetic neuralgia (22). The combined NNTs for pregabalin in the management of painful diabetic neuropathy and postherpetic neuralgia were 4.5 and 4.2, respectively (27). Pregabalin has also been studied in chronic central $\mathrm{NeP}$ following spinal cord injury, with evidence of significant pain relief $(29,30)$. However, a study investigating pregabalin in the treatment of $\mathrm{NeP}$ associated with chronic lumbosacral radiculopathy was negative (31), as was a recent trial involving refractory painful diabetic neuropathy (32). A study investigating the safety and efficacy of pregabalin in patients with central poststroke pain showed no significant improvement in the primary end point of pain intensity; however, there were some improvements in secondary end points including sleep and anxiety (33).

Carbamazepine remains the drug of first choice for tic douloureux (idiopathic trigeminal neuralgia), but otherwise is not recommended for the management of $\mathrm{NeP}$ (14). Anecdotally, it may also be useful in the management of glossopharyngeal neuralgia (14).

\section{Antidepressant agents}

The tricyclic antidepressants (TCAs) have been shown to provide significant pain relief in various $\mathrm{NeP}$ conditions in many clinical trials, although the sample sizes have tended to be relatively small and most of these trials have used a crossover design (34). The combined NNTs for TCAs in the management of painful diabetic neuropathy and postherpetic neuralgia were 2.1 and 2.8, respectively (27).

The serotonin noradrenaline reuptake inhibitors (SNRIs), duloxetine and venlafaxine, have mainly been studied in painful diabetic neuropathy. Duloxetine has demonstrated significant pain relief relative to placebo in three RCTs (28), with a combined NNT of 5.0 (27). A recent study investigating duloxetine in the management of chemotherapy-induced painful peripheral neuropathy showed a significant reduction in pain intensity relative to placebo, with a moderate effect size of 0.51 (35). However, duloxetine has also been studied in patients with central $\mathrm{NeP}$ due to spinal cord injury or stroke, and the results of this trial were negative (36).

Venlafaxine has shown efficacy in trials involving painful diabetic neuropathy (37) and mixed painful polyneuropathy (38) at doses of $150 \mathrm{mg}$ to $225 \mathrm{mg}$ daily. However, the latter trial, comparing venlafaxine with imipramine, showed a higher proportion of responders in the venlafaxine group. Another trial investigating venlafaxine plus gabapentin in the management of painful diabetic neuropathy showed significant pain relief relative to placebo plus gabapentin (39).

\section{SECOND-LINE ANALGESICS}

Two opioid-type medications are recommended for second-line treatment in the management of $\mathrm{NeP}$.

\section{Tramadol}

Tramadol is a weak opioid agonist and mimics some of the properties of the TCAs in that it inhibits reuptake of noradrenalin and serotonin (40). Tramadol has shown significant benefit in three RCTs investigating painful diabetic neuropathy and mixed NeP syndromes, and has an overall NNT of 4.9 (27). Tramadol leads to less constipation and nausea than other weak opioid analgesics, such as codeine (41), but is more expensive in Canada. Tramadol should be used with caution in conjunction with selective serotonin reuptake inhibitors (SSRIs) because of increased risk of confusion and serotonin syndrome, especially among elderly patients (42).

\section{Opioid analgesics}

A recent meta-analysis of opioids for chronic noncancer pain included 16 randomized trials for chronic $\mathrm{NeP}(43)$. Most of these trials investigated painful diabetic neuropathy and postherpetic neuralgia; however, other trials focused on postamputation pain, sciatica and spinal cord injury pain. The authors found that opioids were more effective than placebo, with a moderate effect size $(0.56)$ for pain. There was a small effect size (0.24) in favour of opioids for function in 13 of these RCTs. The combined NNT for opioids in the management of painful polyneuropathy and postherpetic neuralgia was 2.6 (27).

\section{THIRD-LINE ANALGESICS}

One class of medication is recommended for third-line treatment in the management of $\mathrm{NeP}$ - cannabinoids.

\section{Cannabinoids}

The cannabinoids are analgesic agents with increasing evidence of efficacy in central NeP states, with a combined NNT of 3.4 (27). Dronabinol produced modest analgesia in a trial investigating central pain in multiple sclerosis (44). A 50/50 mixture of tetrahydrocannabinol and cannabidiol in the form of an oral mucosal spray provided significant benefit in another trial investigating central pain in multiple sclerosis (45). A recent systematic review of clinical trials investigating cannabinoids in chronic pain determined that, since 2006, there have been seven highquality (class I and II) studies investigating $\mathrm{NeP}$, and all of these studies except one were positive (46). Four of these studies involved smoked cannabis for the management of HIV neuropathy (two studies), posttraumatic or postsurgical $\mathrm{NeP}$, and combined central and peripheral $\mathrm{NeP}$ states. Two trials involved the cannabinoid oral mucosal spray in the management of multiple peripheral $\mathrm{NeP}$ states with allodynia and painful diabetic neuropathy. The single negative trial compared the synthetic cannabinoid nabilone with dihydrocodeine in peripheral $\mathrm{NeP}$ conditions, and found that dihydrocodeine was superior to nabilone. A more recent trial found that nabilone was effective in relieving symptoms of painful diabetic neuropathy, and also improved disturbed sleep and overall quality of life using an enriched enrollment withdrawal design (47).

\section{FOURTH-LINE ANALGESICS}

Several classes of medications can be considered to be fourth-line treatments for $\mathrm{NeP}$ - SSRIs, other anticonvulsants, methadone, topical lidocaine and miscellaneous agents.

\section{SSRIs}

SSRIs appear to have a weak analgesic effect in the management of NeP. Citalopram (48), paroxetine (49) and escitalopram (50) have been found to be efficacious in the management of painful diabetic neuropathy and painful polyneuropathy independent of their antidepressant effects, but fluoxetine has not (51). However, the combined NNT for all four studies was 6.8 (27). SSRIs used primarily for depression may inhibit the metabolism of TCAs and may increase the risk for serotonin syndrome (52).

\section{Other anticonvulsants}

Lamotrigine has been studied in a variety of peripheral and central $\mathrm{NeP}$ conditions, with variable results. Four studies investigating painful diabetic neuropathy, two studies investigating mixed $\mathrm{NeP}$ and single studies investigating chemotherapy-induced $\mathrm{NeP}$ and spinal cord injury pain were negative. Positive trials investigating HIV-related neuropathy, trigeminal neuralgia and central poststroke pain were reported; however, the sample sizes tended to be small, with significant dropout rates (53). 
Lacosamide is an anticonvulsant agent with sodium channelblocking properties. Lacosamide has been studied in five RCTs investigating painful diabetic neuropathy. There was modest benefit in each trial, with an NNT in the range of 10 to 12. Lacosamide, therefore, has limited efficacy in the treatment of painful diabetic neuropathy (54).

Topiramate and valproic acid have produced mixed results in $\mathrm{NeP}$ trials (27).

\section{Methadone}

Methadone is a synthetic opioid analgesic that may be useful in the management of $\mathrm{NeP}$ related to its $\mathrm{N}$-methyl-D-aspartate antagonist properties (55). Two small RCTs demonstrated benefit from methadone in chronic $\mathrm{NeP}(56,57)$ and survey data suggested efficacy in mixed NeP conditions (58). Methadone has excellent oral bioavailability and a duration of action of at least $8 \mathrm{~h}$ with repetitive dosing. It has an elimination half-life of $24 \mathrm{~h}$ to $36 \mathrm{~h}$, which requires close observation during the titration phase. There are no high-quality RCTs to support the use of methadone in the management of NeP, although guidelines for the use of methadone in the management of chronic pain are available (59). An RCT comparing methadone with other oral opioids is urgently needed.

\section{Topical lidocaine}

Topical lidocaine, as a sodium channel blocker, may be useful in the management of NeP. Systemic side effects are extremely rare as a result of negligible blood levels (60). Topical lidocaine is most practical for patients with localized peripheral $\mathrm{NeP}$, such as postherpetic neuralgia, and remains a second-line agent for this condition based on three positive RCTs investigating lidocaine patch $5 \%$ in the management of postherpetic neuralgia (27). However, recent trials of lidocaine cream or patch $5 \%$ failed to provide benefit in patients with postsurgical peripheral nerve injury (61) or in mixed NeP (62). Therefore, there are conflicting results among placebo-controlled trials investigating topical lidocaine for $\mathrm{NeP}$.

\section{Miscellaneous agents}

Tapentadol is a novel analgesic that has recently become available in Canada. It is pharmacologically similar to tramadol in that it has a dual mechanism of action, but has higher affinity for the mu opioid receptor and has only noradrenergic activity as a monoamine reuptake inhibitor. Tapentadol is approximately one-fifth as potent as oxycodone and has shown efficacy in the management of painful diabetic neuropathy, with greater tolerability (63).

Topical capsaicin may have utility in the management of localized $\mathrm{NeP}$ such as postherpetic neuralgia. Following application to the skin, capsaicin initially causes enhanced sensitivity of nociceptors, followed by persistent desensitization after repeated application of low-concentration $(<1 \%)$ capsaicin or a single application of highconcentration (8\%) capsaicin. Several older studies involving small sample sizes indicate that low-concentration capsaicin provides minimal benefit relative to placebo creams (64). On the other hand, high-concentration capsaicin has recently been studied in four trials investigating postherpetic neuralgia and two trials investigating painful HIV neuropathy using $0.04 \%$ topical capsaicin as the control to maintain blinding. All of these studies showed significant benefit relative to the control for up to 12 weeks after a single application. The NNT for the postherpetic neuralgia studies was in the range of eight to 10 and, for the HIV-neuropathy studies, was approximately 6.2 (65). High-concentration capsaicin requires preapplication of local anesthetic because of the intense burning sensation it produces. This agent is quite expensive and only available in Canada through compassionate release from Health Canada.

Botulinum toxin has been studied in two RCTs involving NeP. Both studies were positive, with significant reduction in pain intensity for 12 to 14 weeks, but these studies were likely underpowered due to small sample sizes. A crossover trial involving patients with painful diabetic neuropathy included only 18 patients (66) and a parallel design trial involving patients with focal painful neuropathies included

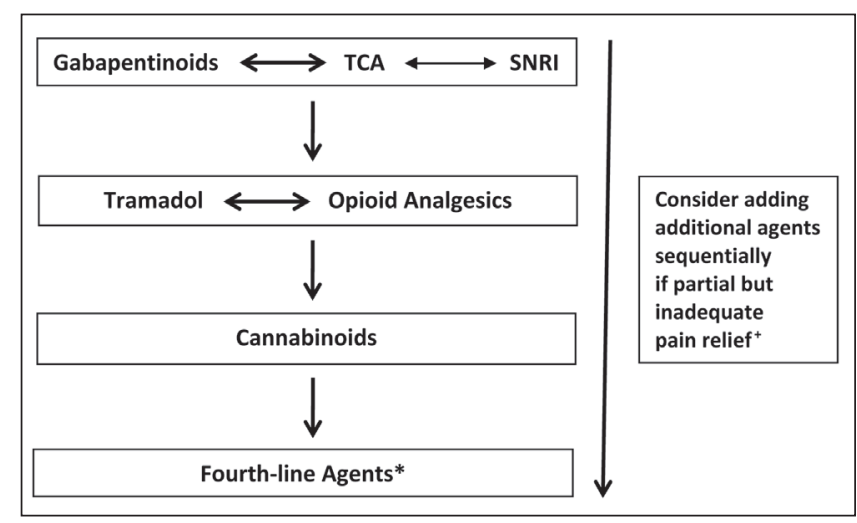

Figure 1) Algorithm for the pharmacological management of neuropathic pain. *Topical lidocaine (second line for postherpetic neuralgia), methadone, lamotrigine, lacosamide, tapentadol, botulinum toxin; ${ }^{+}$Limited randomized controlled trial evidence to support add-on combination therapy. TCA Tricyclic antidepressants; SNRI Serotonin noradrenaline reuptake inhibitors

only 29 patients (67). Evidence for the role of botulinum toxin in the management of $\mathrm{NeP}$, therefore, remains preliminary.

\section{Combination pharmacotherapy}

Combining $\geq 2$ analgesic agents in the management of $\mathrm{NeP}$ is an attractive option because combination pharmacotherapy may improve analgesic efficacy and has the potential to reduce the overall side effect profile if synergistic effects allow for dose reductions of combined drugs (68). A recent Cochrane review of combination pharmacotherapy for the treatment of $\mathrm{NeP}$ in adults identified 21 eligible studies (69). The majority of these studies evaluated the combination of an opioid with gabapentin, pregabalin or a TCA, the combination of gabapentin and nortriptyline, and various topical medications. Meta-analysis was possible for only one combination - gabapentin plus opioid versus gabapentin alone. The meta-analysis demonstrated modest superiority of gabapentin plus opioid versus gabapentin alone, although the combination produced significantly more dropouts due to accentuated side effects related to combination treatments. A recent RCT comparing a combination of standard doses of duloxetine (60 mg daily) and pregabalin (300 mg daily) with high-dose monotherapy (duloxetine $120 \mathrm{mg}$ daily or pregabalin $600 \mathrm{mg}$ daily) found no significant difference in $24 \mathrm{~h}$ average pain, although side effects were comparable (70). Available studies do not support a recommendation of any one specific drug combination for $\mathrm{NeP}$, although these studies do provide a rationale for combination pharmacotherapy.

\section{STEPWISE PHARMACOLOGICAL MANAGEMENT OF NeP}

Figure 1 provides an updated algorithm for the pharmacological management of $\mathrm{NeP}$, and Table 1 provides dosing guidelines for selected agents. Nonpharmacological interventions, including physiotherapy, exercise programs and psychological treatment modalities, are essential to enhance outcome.

Relative to the previous guidelines for management of $\mathrm{NeP}$ published in 2007 (9), duloxetine has been upgraded from a second-line to a first-line agent based on recent evidence of efficacy in the management of chemotherapy-induced painful neuropathy (35) in addition to previously established efficacy in painful diabetic neuropathy.

TCAs, gabapentinoids and SNRIs are, therefore, now all considered to be first-line agents in the management of chronic NeP. TCAs have the advantage of low cost and once-daily dosing, but can produce drowsiness and significant anticholinergic side effects, including dry mouth, constipation and urinary retention, and are, thus, poorly tolerated in the elderly. Secondary amine TCAs (nortriptyline 
TABLE 1

Dosing regimens for selected agents for neuropathic pain

\begin{tabular}{|c|c|c|c|c|}
\hline Agent & Starting dose and titration & Usual maintenance dose & Adverse effects & Comments \\
\hline \multicolumn{5}{|c|}{ Tricyclic antidepressants } \\
\hline $\begin{array}{l}\text { Amitriptyline } \\
\text { Nortriptyline } \\
\text { Desipramine }\end{array}$ & $\begin{array}{c}10-25 \text { mg/day; increase } \\
\text { weekly by } 10 \text { mg/day }\end{array}$ & 10-100 mg/day & $\begin{array}{l}\text { Drowsiness, confusion, } \\
\text { orthostatic hypotension, dry } \\
\text { mouth, constipation, urinary } \\
\text { retention, weight gain, } \\
\text { arrhythmia }\end{array}$ & $\begin{array}{l}\text { Amitriptyline more likely to produce drowsiness } \\
\text { and anticholinergic side effects; contraindicated } \\
\text { in patients with glaucoma, symptomatic } \\
\text { prostatism and significant cardiovascular disease }\end{array}$ \\
\hline
\end{tabular}

\section{Serotonin noradrenaline reuptake inhibitors \\ Venlafaxine $\quad 37.5 \mathrm{mg} /$ day; increase weekly $150-225 \mathrm{mg} / \mathrm{day}$ by $37.5 \mathrm{mg} /$ day

\begin{tabular}{|c|c|c|}
\hline Duloxetine & $\begin{array}{l}30 \mathrm{mg} / \text { day; increase weekly } \\
\text { by } 30 \mathrm{mg} / \text { day }\end{array}$ & 60-120 mg/day \\
\hline \multicolumn{3}{|c|}{ Anticonvulsants } \\
\hline Gabapentin & $\begin{array}{l}\text { 100-300 mg/day; increase } \\
\text { weekly by } 100-300 \mathrm{mg} / \text { day }\end{array}$ & $\begin{array}{l}300-1200 \mathrm{mg} \text { three times } \\
\text { daily }\end{array}$ \\
\hline
\end{tabular}

Pregabalin 25-150 mg/day; increase 150-300 mg twice daily weekly by $25-150 \mathrm{mg} /$ day

Carbamazepine $100 \mathrm{mg}$ once daily; increase weekly by $100-200 \mathrm{mg} /$ day

200-400 mg three times daily Drowsiness, dizziness,

Nausea, dizziness, drowsiness, hyperhidrosis, hypertension ataxia, dry mouth

\begin{abstract}
$30-120 \mathrm{mg}$ every $12 \mathrm{~h}$
20-60 mg every $12 \mathrm{~h}$

25-100 $\mathrm{\mu g} / \mathrm{h}$ patch

6-24 mg every $12 \mathrm{~h}$
\end{abstract}

Hydromorphone $3 \mathrm{mg}$ every $12 \mathrm{~h}$

Others

Tramadol

$50 \mathrm{mg} /$ day; increase weekly by $50 \mathrm{mg} /$ day

Lidocaine

Tetrahydrocannabinol/ cannabidiol (nabiximols)

Nabilone $24 \mathrm{~h}$ period

\author{
1-2 sprays every $4 \mathrm{~h}$, \\ maximum 4 sprays on \\ day 1 , titrate slowly \\ 0.25-0.5 mg at night; increase $3 \mathrm{mg}$ twice daily \\ weekly by $0.5 \mathrm{mg} /$ day \\ Two sprays four times daily
}

Sedation, nausea, constipation, Contraindicated in patients with glaucoma blurred vision, ataxia, headache, nausea, rash

Drowsiness, dizziness, peripheral edema, visual blurring

Drowsiness, dizziness, peripheral edema, visual blurring

Nausea, vomiting, sedation, dizziness, urinary retention, constipation
Dosage adjustments required in renal failure and
in elderly patients

Similar adjustments in renal failure

Drug of first choice for tic douloureux (idiopathic trigeminal neuralgia); as an enzyme inducer, may interfere with activity of other drugs such as warfarin; monitoring of blood counts and liver function tests recommended

Constipation requires concurrent bowel regimen; monitor for addiction
Ataxia, sedation, constipation, May lower seizure threshold; use with caution in seizures, orthostatic hypotension

$5 \%$ patches or gel applied to painful areas for $12 \mathrm{~h}$ in a

Dizziness, fatigue, nausea, euphoria

Dizziness, drowsiness, dry mouth patients with epilepsy

Most useful for postherpetic neuralgia; has virtually no systemic side effects; lidocaine patches not available in Canada

Approved in Canada for neuropathic pain associated with multiple sclerosis; causes positive urine drug testing for cannabinoids; monitor application site (oral mucosa)

Approved in Canada for nausea and vomiting associated with chemotherapy. Does not test positive for cannabinoids on routine urine drug testing and desipramine) are better tolerated than tertiary amine TCAs (amitriptyline and imipramine) with comparable analgesic efficacy (71). Cardiac toxicity is also a risk factor with TCAs, which are relatively contraindicated in patients with a history of arrhythmia (72).

Gabapentin and pregabalin appear to be similar in their mechanisms of action and side-effect profiles, and allow for more rapid titration than antidepressant agents. Pregabalin carries the advantage of twice-daily dosing and linear pharmacokinetics relative to gabapentin. Gabapentinoids in general have few drug interactions, but are dependent on renal excretion and, therefore, require dosage reductions in patients with renal insufficiency (72).

If a TCA fails or is contraindicated, the use of a gabapentinoid or an SNRI, such as duloxetine, should be considered. If one of the latter agents provides only partial pain relief, it is reasonable to add the other agent because there is evidence that combination pharmacotherapy can be helpful (68).
When first-line medications fail or provide inadequate pain relief, tramadol or a conventional opioid analgesic may be useful as a secondline treatment. It is also reasonable to consider a short-acting opioid, such as codeine or oxycodone (sometimes combined with acetaminophen), for breakthrough pain during titration of a first-line agent if needed for severe pain. Controlled-release opioid analgesics are considered to be second-line agents in the management of $\mathrm{NeP}$ because of their extensive side-effect profile and the risk of opioid misuse, abuse and addiction leading to cautionary prescribing and monitoring. A recent meta-analysis of $62 \mathrm{RCT}$ s found that the most common adverse effects associated with opioids were nausea (28\%), constipation (25\%), drowsiness (24\%), dizziness (18\%) and vomiting (15\%) (43). Although tolerance may occur to several of these side effects, there is very little tolerance to constipation and almost all patients placed on a controlledrelease opioid analgesic require a bowel regimen with continued monitoring of bowel function. Potential long-term complications of opioid 
analgesia include opioid-induced hyperalgesia (73) and opioid-induced endocrinopathy $(74,75)$. Endocrine effects manifest as hypogonadism and increased risk for osteopenia. Monitoring for risk for opioid addiction is also challenging. A review suggested that aberrant drug-related behaviours and illicit drug use occurred in $10 \%$ to $15 \%$ of patients receiving chronic opioid therapy (76). Canadian guidelines for the safe and effective use of opioids for chronic noncancer pain, including monitoring for addiction, are strongly recommended (77).

The cannabinoids have now advanced to third-line agents in the management of chronic NeP based on increasing evidence of efficacy in multiple pain models including HIV neuropathy, post-traumatic and postsurgical NeP, painful diabetic neuropathy and spinal cord injury pain $(46,47)$. However, the cannabinoids also require close monitoring, are contraindicated in patients with a history of psychosis and most of these agents, including the oral mucosal spray, are expensive.

Fourth-line agents in the management of $\mathrm{NeP}$ include methadone, tapentadol and anticonvulsants, with lesser evidence of efficacy such as lacosamide, lamotrigine and topiramate. Topical lidocaine has been relegated to fourth-line status because of conflicting evidence of efficacy except in the management of postherpetic neuralgia, for which it remains a second-line option.

It is more challenging to provide a stepwise systematic approach to the management of central $\mathrm{NeP}$ because of the relative paucity of highquality studies and conflicting evidence of efficacy. For instance, lamotrigine was found to be useful in the management of central poststroke pain, but not for spinal cord injury pain (53). Similarly, pregabalin has been found to be efficacious in the management of spinal cord injury pain $(29,30)$, but not in central poststroke pain (33). However, it is reasonable to consider the gabapentinoids and cannabinoids as first-line agents for the management of spinal cord injury pain (78), and TCAs (79) and lamotrigine (53) in the management of central poststroke pain.

\section{INVASIVE TECHNIQUES IN THE MANAGEMENT OF NeP}

Although interventional techniques for $\mathrm{NeP}$ management are beyond the scope of the present consensus statement, they are usually considered when standard pharmacological treatments fail and psychological screening shows emotional stability. Intravenous lidocaine infusions are generally safe, but evidence of efficacy is limited to one to two weeks postinfusion (80). Two recent comprehensive reviews of interventional management of $\mathrm{NeP}$ concluded that weak recommendations could be made for epidural steroid injections for radiculopathy, and spinal cord stimulation for failed back surgery syndrome and complex regional pain syndrome type $1(81,82)$.

\section{SUMMARY}

The present updated consensus statement provides a stepwise pharmacological approach to the management of NeP. Gabapentinoids, TCAs and SNRIs represent first-line treatments for $\mathrm{NeP}$ either individually or in combination. When these agents fail, conventional opioid analgesics and tramadol provide important avenues of treatment, bearing in mind their associated risks and adverse effect profiles. Cannabinoids are now considered to be third-line agents based on recent evidence of efficacy, but also require judicious prescribing practices. Novel treatment approaches are required to improve our management of $\mathrm{NeP}$ and further studies are necessary to examine head-to-head comparisons among analgesics, combinations of analgesics, long-term outcomes and treatments of pediatric, geriatric and central NeP.

ACKNOWLEDGEMENTS: The consensus meeting and manuscript preparation for this consensus statement were conducted under the direction of the Neuropathic Pain Special Interest Group of the CPS. Funding for this project was provided by this group.

COMPETING INTERESTS: DE Moulin has received research grant funding from Pfizer Canada and Purdue Pharma (Canada), and has received honoraria for consultations and speaker fees for educational presentations from Pfizer Canada, Purdue Pharma (Canada), Merck-Frosst Canada, Janssen and Eli Lilly. A Boulanger has received honoraria for consultations and speaker fees for educational presentations from Pfizer Canada, Purdue Pharma (Canada), Merck-Frosst Canada, Janssen and Eli Lilly. AJ Clark has received honoraria for consultations from Pfizer Canada. H Clarke has received a peer-reviewed grant from the Pfizer Neuropathic Pain Award Competition, and has received grants from the Canadian Anesthesiology Society, Physicians' Services Incorporated Foundation and support from the Canadian Institutes of Health Research and Merit Award Support from the University of Toronto. T Dao has no competing interests to declare. GA Finley has provided consultation on research design to Johnson \& Johnson $P R \& D$ on studies of tramadol, and to Janssen $R \& D$ on studies of tapentadol. He has no financial investment in the outcomes of these trials. A Furlan acknowledges funding from CIHR New Investigator Award. I Gilron is a member of the IASP NeuPSIG Neuropathic Pain Treatment Committee and part of the Analgesic, Anesthetic and Addiction Clinical Trial Translations, Innovations, Opportunities and Networks (ACTTION) partnership, and has received support from Pfizer, Aventis Pharma, Novopharm, PharmaScience, Apotex, Merck-Frosst, Johnson \& Johnson, Ortho-McNeill and Janssen-Ortho, and grants from the Canadian Institutes of Health Research, Physicians' Services Incorporated Foundation and Queen's University. A Gordon has received research grant funding from Allergan, Pfizer Canada and Eli Lilly, and has received honoraria for consultations and speaker fees for educational presentations from Allergen, Purdue Pharma (Canada), Pfizer Canada, Eli Lilly, Janssen and AstraZeneca. P Morley-Forster has no competing interests to declare. BJ Sessle has received grant funding from NIH, CIHR, CFI and Pfizer Canada and consultant fees from Eli Lilly, Boehringer and Pfizer Canada. P Squire has received honoraria for consultations and speaker fees from Eli Lilly, Pfizer Canada, Pfizer Canada, Purdue Pharma, Merck-Frosst and Astra Zeneca. J Stinson has no competing interests to declare. P Taenzer has received research grant funding from Pfizer Canada and received an honorarium for consultation from Valeant. A Velly has no competing interests to declare. MA Ware has received grant support from Pfizer, Valeant and Purdue, and speakers fees from Lilly and Boehringer. EL Weinberg has received honoraria for consultations and/or speaker fees for educational presentations from Janssen, Lilly, Medical Futures Inc, Purdue Pharma and Valeant. OD Williamson has received speaker fees from Eli Lilly Canada Inc, Johnson and Johnson Inc Canada, Mundipharma and Purdue Pharma.

\section{APPENDIX A: SYSTEMATIC LITERATURE SEARCH RESULTS}

Results from Medline and Cochrane databases for pharmacological management of neuropathic pain using TITLE terms 'systematic reviews', 'meta-analyses' and 'guideline OR statement OR recommendation OR consensus' (English language literature since 2007) were tabulated. Articles related to nonpharmacological interventions, cancer pain due to tumour infiltration of nerve, and prevention and epidemiology of neuropathic pain were excluded. A total of 87 systematic reviews and meta-analyses, and 21 consensus statements/guidelines were reviewed. A full list of the included references is available from the authors on request.

\section{APPENDIX B: AUTHOR AFFILIATIONS}

- DE Moulin, Departments of Clinical Neurological Sciences and Oncology, Western University, London, Ontario

- A Boulanger, Associate Professor of Anesthesiology, Montreal University, Montreal, Quebec

- AJ Clark, Medical Director Pain Services, Capital Health; Professor of Anesthesia, Pain Management and Perioperative Medicine, Dalhousie University, Halifax, Nova Scotia

- H Clarke, Medical Director, Pain Research Unit, Toronto General Hospital, University Health Network; Assistant Professor, Department of Anesthesia, University of Toronto, Toronto, Ontario

- T Dao, Associate Professor, Faculty of Dentistry, University of Toronto, Toronto, Ontario

- GA Finley, Professor of Anesthesia and Psychology, Dalhousie University, Dr Stewart Wenning Chair in Pediatric Pain Management, IWK Health Centre, Halifax, Nova Scotia 
- A Furlan, Assistant Professor, Division of Physiatry, Department of Medicine, University of Toronto, Toronto, Ontario

- I Gilron, Director of Clinical Pain Research; Professor of Anesthesiology \& Perioperative Medicine, and Biomedical \& Molecular Sciences; Center for Neuroscience Studies, Queen's University, Kingston, Ontario

- A Gordon, Director, Wasser Pain Management Centre; Associate Professor, University of Toronto, Toronto, Ontario

- PK Morley-Forster, Professor, Department of Anesthesiology and Peri-Operative Medicine, Western University, London, Ontario

- BJ Sessle, Professor and Canada Research Chair, Faculties of Dentistry and Medicine; Centre for the Study of Pain, University of Toronto, Toronto, Ontario

- P Squire, Assistant Clinical Professor, University of British Columbia, Vancouver, British Columbia

\section{REFERENCES}

1. Treede RD, Jensen TS, Campbell JN, et al. Neuropathic pain: Redefinition and a grading system for clinical and research purposes. Neurology 2008;70:1630-5.

2. Daousi C, MacFarlane IA, Woodward A, Nurmikko TJ, Bundred PE, Benbow SJ. Chronic painful peripheral neuropathy in an urban community: A controlled comparison of people with and without diabetes. Diabet Med 2004;21:976-82.

3. Jung BF, Ahrendt GM, Oaklander AL, Dworkin RH. Neuropathic pain following breast cancer surgery: Proposed classification and research update. Pain 2003;104:1-13.

4. Foley KM. Opioids and chronic neuropathic pain. N Engl J Med 2003;348:1279-81.

5. Gilron I, Watson CP, Cahill CM, et al. Neuropathic pain: A practical guide for the clinician. CMAJ 2006;175:265-75.

6. Bouhassira D, Lanteri-Minet M, Attal N, Laurent B, Touboul C. Prevalence of chronic pain with neuropathic characteristics in the general population. Pain 2008;136:380-7.

7. Torrance N, Smith BH, Bennett MI, Lee AJ. The epidemiology of chronic pain of predominantly neuropathic origin. Results from a general population survey. J Pain 2006;7:281-9.

8. Sadosky A, McDermott AM, Brandenburg NA, Strauss M. A review of the epidemiology of painful diabetic neuropathy, postherpetic neuralgia and less commonly studied neuropathic pain conditions. Pain Pract 2008;8:45-56.

9. Hall GC, Morant SV, Carroll D, Gabriel ZL, McQuay HJ. An observational descriptive study of the epidemiology and treatment of neuropathic pain in a UK general population. BMC Fam Pract 2013;14:28.

10. Kautio AL, Haanpaa M, Kautianen H, Kalso E, Saarto T. Burden of chemotherapy-induced neuropathy - a cross-sectional study. Support Care Cancer 2011;19:1991-1998.

11. Moulin DE, Clark AJ, Gilron I, et al. Pharmacological management of chronic neuropathic pain - Consensus statement and guidelines from the Canadian Pain Society. Pain Res Manag 2007;12:13-21.

12. Dworkin RH, Panarites CJ, Armstrong EP, Malone DC, Pham SV. Is treatment of postherpetic neuralgia in the community consistent with evidence-based recommendations? Pain 2012;153:869-75

13. Shekelle P, Eccles MP, Grimshaw JM, Woolf SH. When should clinical guidelines be updated? BMJ 2001;323:155-7.

14. Zakrzewska JM. Medical management of trigeminal neuropathic pains. Expert Opin Pharmacother 2010;11:1239-54.

15. Ashamn EJ, Gronseth GS. Level of evidence reviews - three years of progress. Neurology 2012;79-13-4.

16. Dworkin RH, Turk DC, Basch E, et al. Considerations for extrapolating evidence of acute and chronic pain analgesic efficacy. Pain 2011;152:1705-8.

17. Harden RN, Bruehl SP. Diagnostic criteria: The statistical derivation of the four criterion factors. In: Wilson P, Stanton-Hicks M, Harden RN, eds. CRPS: Current Diagnosis and Therapy (Progress in Pain Research and Management, Volume 32). Seattle: IASP Press, 2005:45-58

18. Bouhassira D, Attal N, Alchaar H, et al. Comparison of pain syndromes associated with nervous or somatic lesions and development of a new neuropathic pain diagnostic questionnaire (DN4). Pain 2005;114:29-36.
- J Stinson, Scientist, Child Health Evaluation Sciences, The Hospital for Sick Children, Associate Professor, Lawrence S Bloomberg Faculty of Nursing, University of Toronto; The Peter Gilgan Centre for Research and Learning, Toronto, Ontario

- P Taenzer, Adjunct Assistant Professor, Departments of Psychiatry, Medicine and Oncology, Faculty of Medicine, University of Calgary, Calgary, Alberta

- A Velly, McGill University, Faculty of Dentistry, Division of Clinical Epidemiology and Department of Dentistry, Jewish General Hospital, Montreal, Quebec

- MA Ware, Associate Professor, Anesthesia and Family Medicine, McGill University, Montreal, Quebec

- EL Weinberg, Toronto, Ontario

- OD Williamson, Jim Pattison Outpatient Care and Surgery Centre, Pain Management Clinic, Fraser Health Authority, Surrey, British Columbia

19. Bennett MI, Smith BH, Torrance N, Potter J. The S-LANSS score for identifying pain of predominantly neuropathic origin: Validation for use in clinic and postal research. J Pain 2005;6:149-58.

20. Cohen J. Statistical Power Analysis for the Behavioural Sciences. New York, San Francisco, London: Academic Press, 1988.

21. Taylor CP. The biology and pharmacology of calcium channel alpha2-delta proteins. CNS Drug Rev 2004;10:183-8.

22. Attal N, Cruccu G, Baron R, et al. EFNS guidelines on the pharmacological treatment of neuropathic pain: 2010 revision. Eur J Neurol 2010;17:1113-23.

23. Gordh TE, Stubhaug A, Jensen TS, et al. Gabapentin in traumatic nerve injury pain: A randomized, double-blind, placebo-controlled, crossover, multi-centre study. Pain 2008;138:255-66.

24. Rao RD, Michalak JC, Sloan JA, et al. Efficacy of gabapentin in the management of chemotherapy-induced peripheral neuropathy: A phase 3 randomized, double-blind, placebo-controlled, crossover trial (N00C3). Cancer 2007;110:2110-8.

25. Rintala DH, Holmes SA, Courtade D, et al. Comparison of the effectiveness of amitriptryline and gabapentin on chronic neuropathic pain in persons with spinal cord injury. Arch Phys Med Rehabil 2007;88:1547-60.

26. Smith DG, Ehde DM, Hanley MA, et al. Efficacy of gabapentin in treating chronic phantom limb and residual limb pain. J Rehabil Res Dev 2005;42:645-54.

27. Finnerup NB, Sindrup SH, Jensen TS. The evidence for pharmacological treatment of neuropathy pain. Pain 2010;150:573-81.

28. Bril V, England J, Franklin GM, et al. Evidence-based guideline Treatment of painful diabetic neuropathy. Neurology 2011:1-8.

29. Siddall PJ, Cousins MJ, Otte A, et al. Pregabalin in central neuropathic pain associated with spinal cord injury: A placebocontrolled trial. Neurology 2006;67:1792-800.

30. Vranken JH, Dijkgraaf MG, Kruis MR, et al. Pregabalin in patients with central neuropathic pain: A randomized, double-blind, placebo-controlled trial of a flexible-dose regimen. Pain 2008;136:150-7.

31. Baron R, Freynhagen R, Tolle TR, et al. The efficacy and safety of pregabalin in the treatment of neuropathic pain associated with chronic lumbosacral radiculopathy. Pain 2010;150:420-7.

32. Philip R, Huffman C, Toth C, et al. Pregabalin in patients with inadequately treated painful diabetic peripheral neuropathy: A randomized withdrawal trial. Clin J Pain 2014;30:379-90.

33. Kim JS, Bashford G, Murphy TK, et al. Safety and efficacy of pregabalin in patients with central post-stroke pain. Pain 2011;152:1018-23.

34. Finnerup NB, Otto M, McQuay HJ, Jensen TS, Sindrup SH. Algorithm for neuropathic pain treatment: An evidence-based proposal. Pain 2005;118:289-305.

35. Lavoie Smith EM, Pang H, Cirrincione C, et al. Effect of duloxetine on pain, function and quality of life among patients with chemotherapy-induced painful peripheral neuropathy. JAMA 2013;309:1359-67.

36. Vranken JH, Hollmann MW, van der Vegt MH, et al. Duloxetine in patients with central neuropathic pain caused by spinal cord injury or stroke: A randomized, double-blind, placebo-controlled trial. Pain 2011;152:267-73. 
37. Rowbotham MC, Goli V, Junz NR, Lei D. Venlafaxine extended release in the treatment of painful diabetic neuropathy: A double-blind, placebo-controlled study. Pain 2004;100:697-706. (Erratum in 2005;113:248).

38. Sindrup SH, Bach FW, Madsen C, Gram LF, Jensen TS. Venlafaxine versus imipramine in painful polyneuropathy: A randomized, controlled trial. Neurology 2003;60:1284-9.

39. Simpson DA. Gabapentin and venlafaxine for the treatment of painful diabetic neuropathy. J Clin Neuromuscul Dis 2001;3:53-62.

40. Abramowicz M. Tramadol - a new oral analgesic. Med Lett Drugs Ther 1993;37:59-62.

41. Smith AB, Ravikumar TS, Kamin M, et al. Combination tramadol plus acetaminophen for postsurgical pain. Am J Surg 2004;187:521-7.

42. Hollingshead J, Duhmke RM, Cornblath DR. Tramadol for neuropathic pain. Cochrane Database Syst Rev 2006;(3):CD003726.

43. Furlan AD, Chaparro LE, Irvin E, Mailis-Gagnon A. A comparison between enriched and nonenriched enrollment randomized withdrawal trials of opioids for chronic noncancer pain. Pain Res Manag 2011;16:337-51.

44. Svendsen KB, Jensen TS, Bach FW. Does the cannabinoid dronabinol reduce central pain in multiple sclerosis? Randomized double-blind placebo-controlled crossover trial. BMJ 2004:329:253.

45. Rog DJ, Nurmikko TJ, Friede T, Young CA. Randomized, controlled trial of cannabis-based medicine in central pain in multiple sclerosis. Neurology 2005;65:812-9.

46. Lynch ME, Campbell F. Cannabinoids for treatment of chronic non-cancer pain: A systematic review of randomized trials. Br J Clin Pharmacol 2011;72:735044.

47. Toth C, Mawani S, Brady S, et al. An enriched-enrolment, randomized withdrawal, flexible-dose, double-blind, placebo-controlled, parallel assignment efficacy study of nabilone as adjuvant in the treatment of diabetic peripheral neuropathic pain. Pain 2012;153:2073-82.

48. Sindrup SH, Bjerre U, Dejgaard A, et al. The selective serotonin reuptake inhibitor citalopram relieves the symptoms of diabetic neuropathy. Clin Pharmacol Ther 1992;52:547-52.

49. Sindrup SH, Cram LF, Brosen K, Eshoj O, Mogensen EF. The selective serotonin reuptake inhibitor paroxetine is effective in the treatment of diabetic neuropathy symptoms. Pain 1990;42:135-44.

50. Otto M, Bach FW, Jensen TS, Brosen K, Sindrup SH. Escitalopram in painful polyneuropathy: A randomized, placebo-controlled, crossover trial Pain 2008;139:275-83.

51. Max MB, Lynch SA, Muir J, et al. Effects of desipramine, amitriptyline and fluoxetine on pain in diabetic neuropathy. N Engl J Med 1992;326:1250-6.

52. Sproule BA, Naranjo CA, Brenmer KE, Hassan PC. Selective serotonin reuptake inhibitors and CNS drug interactions. A critical review of the evidence. Clin Pharmacokinet 1997;33:454-71.

53. Wiffen PJ, Derry S, Moore RA. Lamotrigine for acute and chronic pain. Cochrane Database Syst Rev 2011;(2):CD006044.

54. Hearn L, Derry S, Moore RA. Lacosamide for neuropathic pain and fibromyalgia in adults. Cochrane Database Syst Rev 2012;(2):CD009318

55. Gorman A, Elliott K, Inturrisi C. The d- and l-isomers of methadone bind to the non-competitive site on the N-methyl-Daspartate (NMDA) receptor in rat forebrain and spinal cord. Neurosci Lett 1997;223:5-8.

56. Morley JD, Bridson J, Nash TP, et al. Low dose methadone has an analgesic effect in neuropathic pain: A double-blind randomized controlled crossover trial. Palliat Med 2003;17:576-87.

57. Gagnon B, Almahrezi A, Schreier G. Methadone in the treatment of neuropathic pain. Pain Res Manag 2003;8:149-54.

58. Moulin DE, Palma D, Watling C, Schulz V. Methadone in the management of intractable neuropathic noncancer pain. Can J Neurol Sci 2005;32:340-3.

59. Lynch M. A review of the use of methadone for the treatment of chronic noncancer pain. Pain Res Manag 2005;10:133-44.

60. Gammaaitoni AR, Davis MW. Pharmacokinetics and tolerability of lidocaine patch $5 \%$ with extended dosing. Ann Pharmacother 2002;36:236-40.
61. Cheville AL, Sloan JA, Northfelt DW, et al. Use of a lidocaine patch in the management of postsurgical neuropathic pain in patients with cancer: A phase III double-blind crossover study (N01CB). Support Care Cancer 2009;17:451-60.

62. Ho KY, Huh BK, White WD, Yeh CC, Miller EJ. Topical amitriptyline versus lidocaine in the treatment of neuropathic pain. Clin J Pain 2008;24:51-5.

63. Schwartz S, Etropolski M, Shapiro DY, et al. Safety and efficacy of tapentadol ER in patients with painful diabetic peripheral neuropathy: Results of a randomized-withdrawal, placebo-controlled trial. Curr Med Res Opin 2011;27:151-62.

64. Derry S, Moore RA. Topical capsaicin (low concentration) for chronic neuropathic pain in adults. Cochrane Database Syst Rev 2012;(9):CD010111.

65. Derry S, Rice, AS, Cole P, Tan T, Moore RA. Topical capsaicin (high concentration) for chronic neuropathic pain in adults. Cochrane Database Syst Rev 2013;(2):CD007393.

66. Yuan R-Y, Sheu J-J, Yu J-M, et al. Botulinum toxin for diabetic neuropathic pain. Neurology 2009;72:1473-8.

67. Ranoux D, Attal N, Morain F, Bouhassira D. Botulinum toxin type $A$ induces direct analgesic effects in chronic neuropathic pain. Ann Neurology 2008;64:274-83.

68. Gilron I, Jensen TS, Dickenson AH. Combination pharmacotherapy for management of chronic pain: From bench to bedside. Lancet Neurol 2013;12:1084-95.

69. Chaparro LE, Wiffen PJ, Moore RA, Gilron I. Combination pharmacotherapy for the treatment of neuropathic pain in adults. Cochrane Database Syst Rev 2012(7):CD008943.

70. Tesfaye S, Wilhelm S, Lledo A, et al. Duloxetine and pregabalin: High-dose monotherapy or their combination? The "COMBO-DN study" - a multinational, randomized, double-blind, parallel-group study in patients with diabetic peripheral neuropathic pain. Pain 2013;154:2616-25.

71. McQuay HJ, Tramer M, Nye BA, Carroll D, Wiffen PJ, Moore RA. A systematic review of antidepressants in neuropathic pain. Pain 1996;68:217-27.

72. O'Connor AB, Dworkin RH. Treatment of neuropathic pain: An overview of recent guidelines. Amer J Med 2009;122(10A):S22-S32.

73. Mao J. Opioid-induced abnormal pain sensitivity: Implications in clinical opioid therapy. Pain 2002:100:213-7.

74. Daniell HW. Hypogonadism in men consuming sustained-action oral opioids. J Pain 2002;3:377-84.

75. Daniell HW. Opioid endocrinopathy in women consuming prescribed sustained-action opioids for control of nonmalignant pain. J Pain 2008;9:28-36.

76. Fishbain DA, Cole B, Lewis J, Rosomoff HL, Rosomoff RS. What percentage of chronic nonmalignant pain patients exposed to chronic opioid analgesic therapy develop abuse/addiction and/or aberrant drug-related behaviours? A structured evidence-based review. Pain Med 2008;9:444-59.

77. National Opioid Use Guideline Group (NOUGG). Canadian guideline for safe and effective use of opioids for chronic non-cancer pain. <http://nationalpaincentre mcmaster ca/opioid/.2010> (Accessed September 2013).

78. Teasell RW, Mehta W, Aubut JL, et al. A systematic review of pharmacologic treatments of pain after spinal cord injury. Arch Phys Med Rehabil 2010;91:816-31.

79. Leijon G. Boivie J. Central post-stroke pain - a controlled trial of amitriptyline and carbamazepine. Pain 1989;36:27-36.

80. Tremont-Lukats IW, Challapalli V, McNicol ED, et al. Systemic administration of local anesthetics to relieve neuropathic pain: A systematic review and meta-analysis. Anesth Analg 2005;101:1738-49.

81. Mailis A, Taenzer P. Evidence-based guideline for neuropathic pain interventional treatments: Spinal cord stimulation, intravenous infusions, epidural injections and nerve blocks. Pain Res Manag 2012;17:150-8.

82. Dworkin RH, O'Connor AB, Kent J, et al. Interventional management of neuropathic pain: NeuPSIG recommendations. Pain 2013;54:2249-61. 


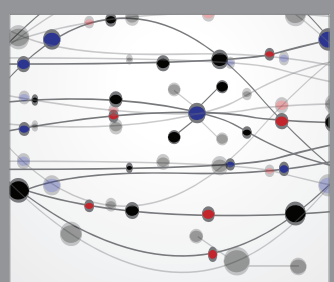

The Scientific World Journal
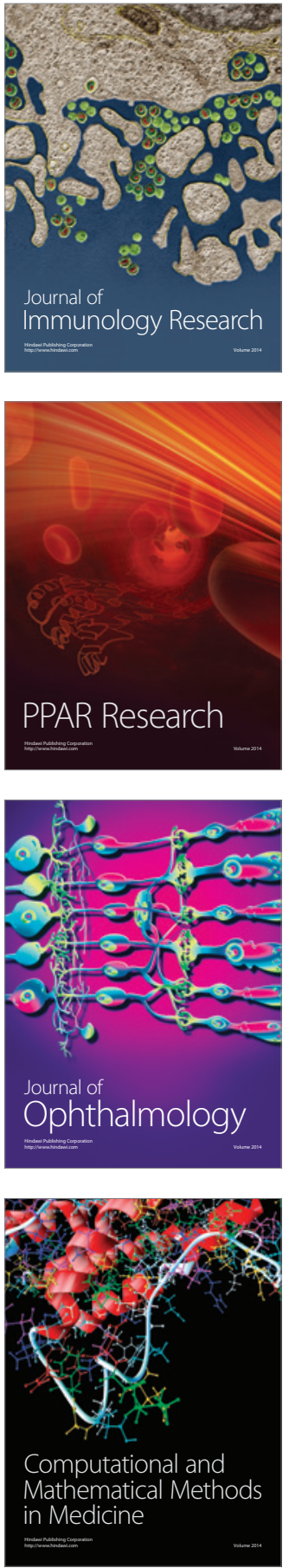

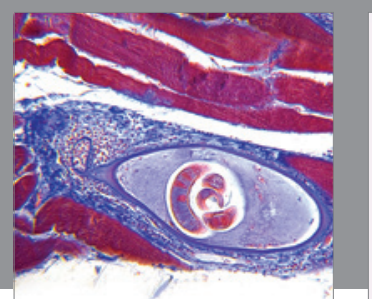

Gastroenterology Research and Practice

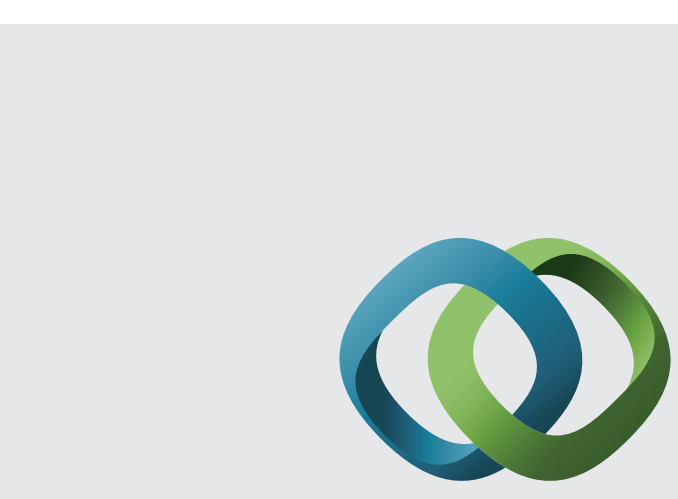

\section{Hindawi}

Submit your manuscripts at

http://www.hindawi.com
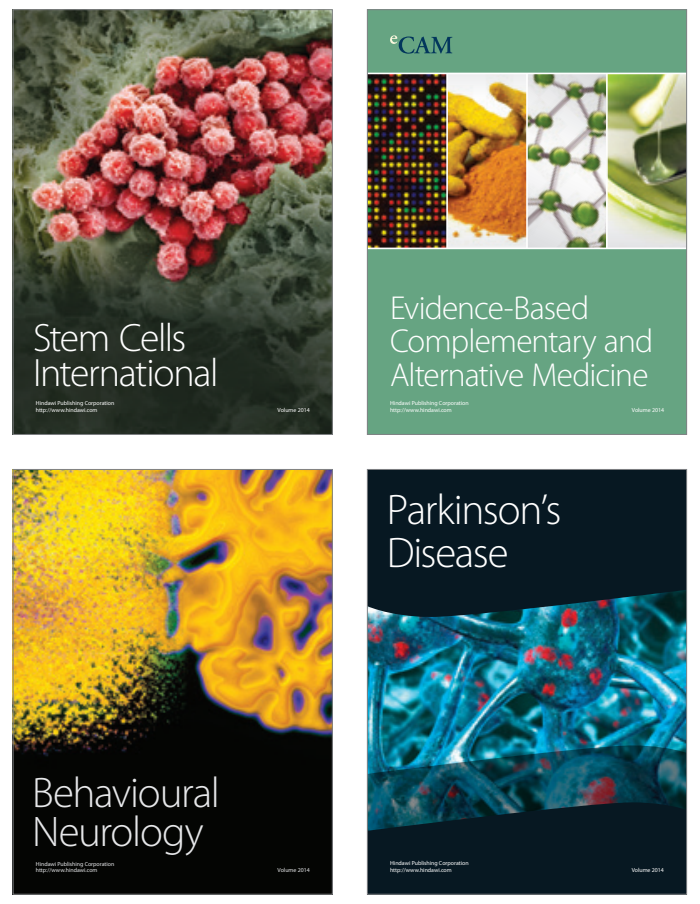
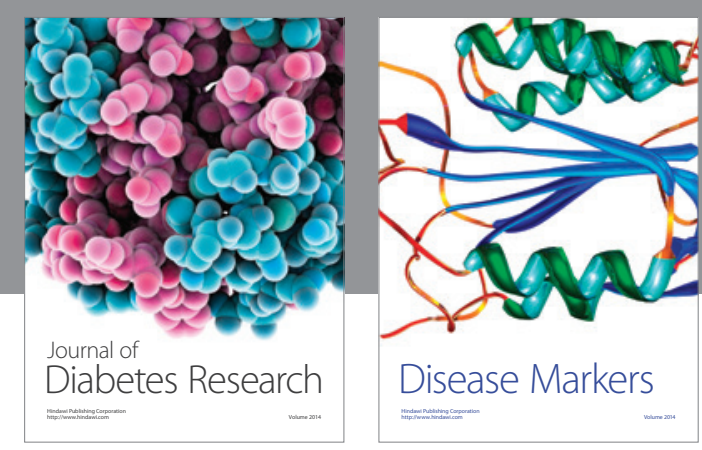

Disease Markers
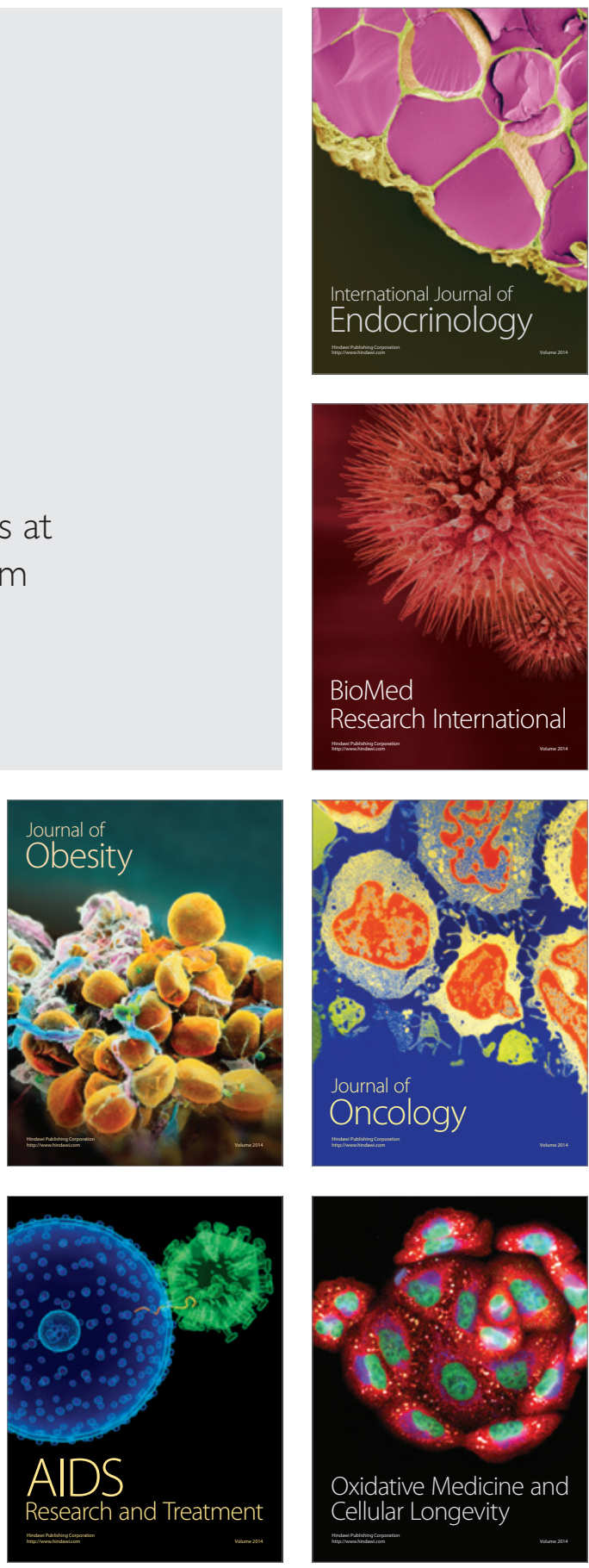